\title{
Microglial activation state exerts a biphasic influence on brain endothelial cell proliferation by regulating the balance of TNF and TGF- $\beta 1$
}

\author{
Jennifer V Welser, Longxuan Li, Richard Milner*
}

\begin{abstract}
Background: Studies of cerebral ischemia and other neuroinflammatory states have demonstrated a strong association between new vessel formation and microglial recruitment and activation, raising the possibility that microglia may be involved in promoting angiogenesis. As endothelial cell proliferation is a fundamental early step in angiogenesis, the aim of this study was to test this hypothesis by examining the influence of microglial secreted factors on brain endothelial cell (BEC) proliferation using BrdU incorporation.

Methods: Primary cultures of mouse BEC, microglia and astrocytes were used in this study. Proliferation of BEC was examined by BrdU incorporation. ELISA was used to quantify TNF and TGF- $\beta 1$ levels within cell culture supernatants.

Results: Microglia regulated BEC proliferation in a biphasic manner; microglia conditioned medium (MG-CM) from resting microglia inhibited, while that from activated microglia promoted BEC proliferation. A screen of microglial cytokines revealed that BEC proliferation was inhibited by TGF- $\beta 1$, but promoted by TNF. ELISA showed that TNF and TGF- $\beta 1$ were both present in MG-CM, and that while TGF- $\beta 1$ dominated in resting MG-CM, TNF levels were massively increased in activated MG-CM, shifting the balance in favor of TNF. Antibody-blocking studies revealed that the influence of MG-CM to inhibit or promote BEC proliferation was largely attributable to the cytokines TGF$\beta 1$ and TNF, respectively.

Conclusion: This data suggests that microglial activation state might be an important determinant of cerebral angiogenesis; inhibiting BEC proliferation and neovascularization in the normal central nervous system (CNS), but stimulating the growth of new capillaries under neuroinflammatory conditions.
\end{abstract}

\section{Background}

Angiogenesis occurs in the central nervous system (CNS) not just during development [1], but also in pathological conditions, including cerebral ischemia [2], neoplasia [3], and neuroinflammation [4,5]. An improved understanding of the factors that control cerebral angiogenesis would be a big step forward in our attempts to regulate angiogenesis for therapeutic means, either to increase blood vessel growth during cerebral ischemia, or to inhibit vessel growth during neoplasia. Angiogenesis is regulated by a plethora of factors, including growth factors [6], cytokines [7], and

\footnotetext{
* Correspondence: rmilner@scripps.edu

Department of Molecular and Experimental Medicine, The Scripps Research Institute, 10550 North Torrey Pines Road, La Jolla, CA 92037, USA
}

extracellular matrix (ECM) molecules [8]. Within the CNS, it has been established that hypoxia promotes angiogenesis by at least two separate pathways. One involves hypoxia inducible factor- $1 \alpha$ (HIF-1 $\alpha$ )-dependent vascular endothelial growth factor (VEGF) release [9], and the other, that involves a HIF-1 $\alpha$-independent COX-2-dependent stimulation of PGE2, leading to angiopoietin-2 release [10]. In addition to soluble factors, ECM proteins also provide important instructional cues in angiogenesis [11], and recent work from our laboratory showing that fibronectin is strongly induced on angiogenic capillaries in the hypoxic CNS [12], as well as on angiogenic vessels in the developing CNS [13], suggests that this protein may also be important for cerebral angiogenesis.
C Biomed Central

() 2010 Welser et al; licensee BioMed Central Ltd. This is an Open Access article distributed under the terms of the Creative Commons Attribution License (http://creativecommons.org/licenses/by/2.0), which permits unrestricted use, distribution, and reproduction in any medium, provided the original work is properly cited. 
In the normal adult CNS, brain endothelial cells (BEC) occupy an angiostatic state, and have the impermeable, tight-barrier characteristics of mature cerebral endothelium [14]. During cerebral ischemia and other neuroinflammatory conditions, vessels in the adult CNS mount an angiogenic response in which BEC proliferate to form new capillary sprouts $[15,16]$. Interestingly, studies of cerebral ischemic tissue have demonstrated a strong association between new vessel formation and microglial recruitment and activation $[17,18]$, raising the possibility that microglia, the principal immune effector cells in the CNS, may actively promote angiogenesis. As endothelial cell proliferation is a fundamental early step in the angiogenic response, the aim of this study was to test this hypothesis by examining the influence of microglial secreted factors on BEC proliferation.

\section{Materials and methods Animals}

The studies described have been reviewed and approved by The Scripps Research Institute Institutional Animal Care and Use Committee. All animals were maintained under pathogen-free conditions in the closed breeding colony of The Scripps Research Institute (TSRI).

\section{Cell Culture}

Pure cultures of mouse brain endothelial cells (BEC) were prepared as previously described [19]. Briefly, brains were removed from 8 week-old C57Bl/6 mice, minced, dissociated for one hour in papain, centrifuged through $22 \%$ BSA to remove myelin, and then endothelial cells cultured in endothelial cell growth media (ECGM) consisting of Hams F12, supplemented with 10\% FBS, Heparin, ascorbic acid, L-glutamine, penicillin/ streptomycin (all from Sigma, St. Louis, MO) and endothelial cell growth supplement (ECGS) (Upstate Cell Signaling Solutions, Lake Placid, NY), on type I collagen (Sigma)-coated 6-well plates. Puromycin $(4 \mu \mathrm{g} / \mathrm{ml}$, Alexis $\mathrm{GmbH}$, Grunberg, Germany) was included in culture media between days 1-3 to remove contaminating cell types. Endothelial cell purity was $>99 \%$ as determined by CD31 in flow cytometry. For all experiments, $\mathrm{BEC}$ were used only for the first passage.

Mixed glial cultures were prepared from 0-2 day old C57Bl/6 mouse pups, as previously described [19], and maintained in poly-D-lysine coated T75 flasks in DMEM containing 10\% fetal bovine serum (FBS) (all from Sigma). After 7-10 days, flasks were mechanically shaken to yield microglia, which were plated into uncoated 6 well plates. Microglial purity was $>99 \%$ as determined by Mac-1 in flow cytometry. Pure astrocyte cultures were prepared as previously described [20], by plating neurospheres into poly-D-lysine coated 6-well plates and maintained in DMEM containing 10\% FBS. Astrocyte purity of these cultures was $>99 \%$ as determined by GFAP immunocytochemistry.

\section{Microglia-conditioned media (MG-CM)}

Microglia were shaken off mixed glial cultures and plated in 6-well plates overnight. Media was then changed to serum-free DMEM containing N1-supplement, L-glutamine and penicillin/streptomycin (all from Sigma). Microglia were left unstimulated or activated with $1 \mu \mathrm{g} /$ $\mathrm{ml}$ lipopolysaccharide (LPS, Sigma) to produce resting and activated MG-CM respectively. After 3 days, media was collected and filtered through a $0.22 \mu \mathrm{m}$ filter before use in BEC studies. Astrocyte conditioned media (A-CM) was prepared in a similar manner.

\section{Brain endothelial cell proliferation assay}

Glass coverslips were coated with collagen I $(10 \mu \mathrm{g} / \mathrm{ml}$, Sigma) for 2 hours, then washed, and BEC plated and cultured until cells reached $\sim 50 \%$ confluence. For investigation of the effect of MG-CM, BEC were cultured in 67\% ECGM and 33\% MG-CM. Control cultures were maintained in 67\% ECGM and 33\% N1-supplemented media. In the function-blocking experiments, the antiTNF and anti-TGF- $\beta 1$ blocking antibodies and control antibodies (R\&D, Minneapolis, MN) were used at $2 \mu \mathrm{g} /$ $\mathrm{ml}$. For the investigation of the influence of cytokines on BEC proliferation, BEC were cultured in ECGM with factors added across a concentration range, with the maximum indicated: IFN- $\alpha\left(10^{3} \mathrm{U} / \mathrm{ml}, \mathrm{PBL}\right.$ Biomedical Labs), IFN- $\gamma(10 \mathrm{U} / \mathrm{ml}, \mathrm{R} \& \mathrm{D}), \mathrm{IL}-6$ (20 ng/ml, R\&D), TNF (20 ng/ml, Genentech, San Francisco, CA), and TGF- $\beta 1$ (20 ng/ml, R\&D). BEC were cultured for 16 hours in the presence of BrdU (Invitrogen, Carlsbad, $\mathrm{CA})$, then fixed in acid/alcohol and processed for BrdU immunocytochemistry according to the manufacturer's instructions. BEC proliferation was assessed by quantifying the number of BrdU-positive cells as a percentage of the total number of cells (Hoechst staining), and the results expressed as the mean \pm SEM of four experiments. Statistical significance was assessed by using Student's $\mathrm{t}$ test, in which $\mathrm{p}<0.05$ was defined as statistically significant.

\section{ELISA analysis of glial cytokine production}

Concentrations of TNF and TGF- $\beta 1$ in microglial and astrocyte conditioned media were quantified by standard ELISA techniques using the Duoset ELISA system (R\&D) according to the manufacturer's instructions. Results represent the mean \pm SEM of 3 experiments, with each sample examined in triplicate within each experiment. 


\section{Results}

Microglial secreted factors regulate BEC proliferation in a biphasic manner

Microglia were purified from mixed glial cultures of postnatal mice, and grown in serum free media for 3 days, in the absence or presence of the activating agent lipopolysaccharide (LPS), to produce microglia-conditioned media (MG-CM) from resting (unstimulated) or activated microglia, respectively. The influence of resting or activated MG-CM on BEC proliferation was examined using BrdU incorporation. As shown in Figure 1, MG-CM had a clear biphasic influence on BEC proliferation rate. Compared to control conditions, resting MG-CM strongly inhibited BEC proliferation (6.4 \pm $2.0 \%$ vs. $20.6 \pm 1.6 \%, \mathrm{p}<0.001)$, while activated MG$\mathrm{CM}$ had the opposite effect $(30.1 \pm 2.0 \%$ vs. $20.6 \pm 1.6 \%$, $\mathrm{p}<0.002)$. The influence of astrocyte-conditioned media (A-CM) was also investigated. This revealed that resting and activated $\mathrm{A}-\mathrm{CM}$ both inhibited $\mathrm{BEC}$ proliferation (resting A-CM $14.5 \pm 1.8 \%$ vs. $20.6 \pm 1.6 \%$, p < 0.05 , and activated A-CM $13.4 \pm 1.0 \%$ vs. $20.6 \pm 1.6 \%$, p $<0.01)$.

\section{TNF and TGF- $\beta 1$ have antagonistic effects on BEC} proliferation

Microglia produce a large number of cytokines, whose production is heavily-dependent on the state of microglial activation [21]. To identify which of these factors might be responsible for the microglial influence on BEC proliferation, we screened a panel of different cytokines for their ability to regulate BEC proliferation. This showed that TNF and TGF- $\beta 1$ had the strongest, though opposing influences on BEC proliferation (Figure 2). TNF promoted BEC proliferation in a dose-dependent manner, which plateaued at a concentration of $10 \mathrm{ng} /$ $\mathrm{ml}$. Compared to control conditions $(21.3 \pm 1.4 \%), 10$ $\mathrm{ng} / \mathrm{ml} \mathrm{TNF}$ increased the rate of BEC proliferation to $32.6 \pm 4.5 \%(\mathrm{p}<0.01)$. In contrast, TGF- $\beta 1$ reduced the rate of BEC proliferation, an effect which plateaued at a concentration of $10 \mathrm{ng} / \mathrm{ml}$. Compared to control conditions, this concentration of TGF- $\beta 1$ reduced BEC proliferation from $20.6 \pm 1.9 \%$ to $13.8 \pm 2.1 \%(\mathrm{p}<0.05)$. IFN$\alpha$, IFN- $\gamma$ and IL- 6 had no significant effect on BEC proliferation at any concentration tested.

\section{Microglia secrete TNF and TGF- $\beta 1$, with the balance} determined by microglial activation state

We have demonstrated that BEC proliferation rate is regulated by $\mathrm{MG}-\mathrm{CM}$ in a biphasic manner; inhibited by resting MG-CM, and promoted by activated MG-CM. Furthermore, we have shown that BEC proliferation is inhibited by TGF- $\beta 1$, but promoted by TNF. While it is known from previous studies that microglia can produce

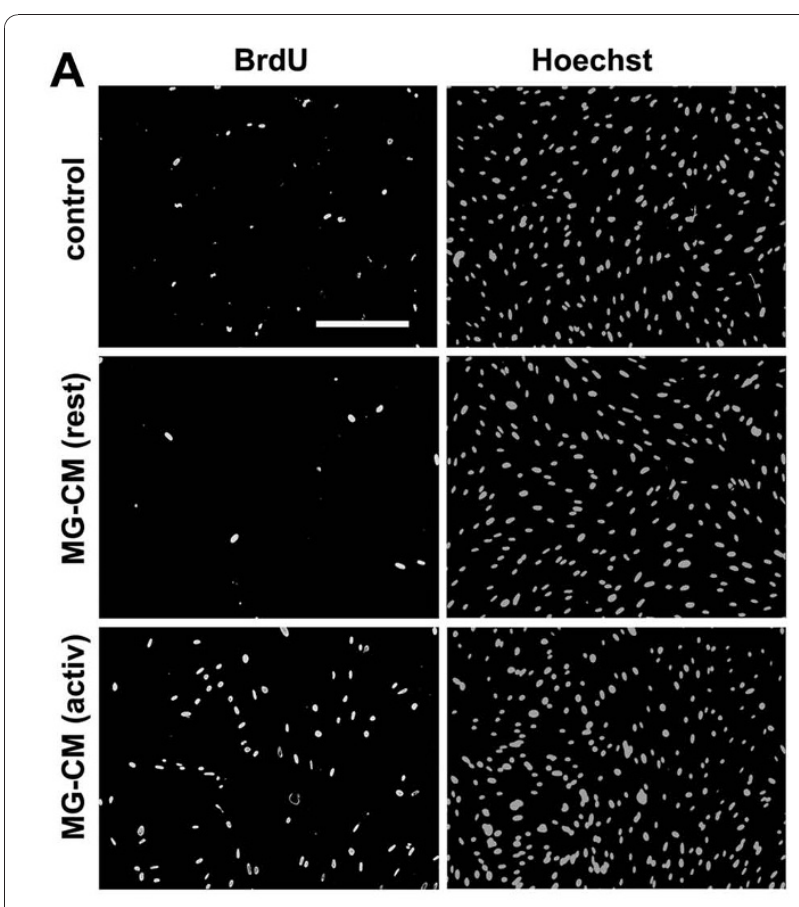

B

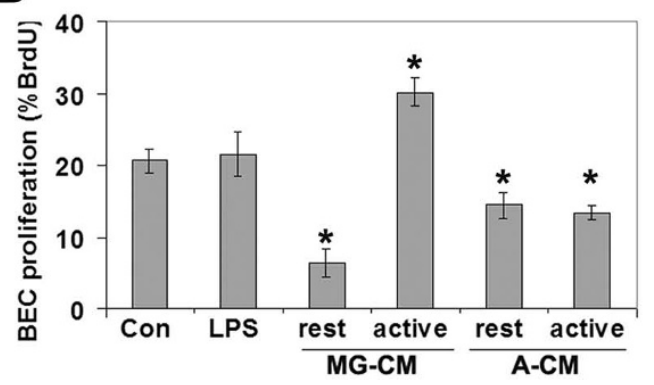

Figure 1 Regulation of BEC proliferation by microglialconditioned medium. A. Dual immunocytochemistry for BrdU and Hoechst demonstrated that BEC proliferation was inhibited by conditioned media from resting microglia (MG-CM (rest)), but promoted by conditioned media from activated microglia (MG-CM (activ)). Scale bar $=100 \mu \mathrm{m}$. B. Quantification of BEC proliferation in response to microglia-conditioned media (MG-CM) and astrocyteconditioned media (A-CM). BEC proliferation was examined over 16 hours, and expressed as the percentage of BEC that incorporated BrdU; all points represent the mean \pm SEM of 4 experiments. MGCM from resting or activated microglia, inhibited or promoted BEC proliferation, respectively. A-CM from resting and activated astrocytes both inhibited BEC proliferation. $p<0.05$.

these two cytokines [22,23], we next used ELISA to investigate in our own cultures, whether MG-CM contained TNF or TGF- $\beta 1$, and how this expression is regulated by LPS. As shown in Figure 3A, TNF was present in resting $\mathrm{MG}-\mathrm{CM}(27.7 \pm 8.6 \mathrm{pg} / \mathrm{ml})$, but strongly increased (50-fold) in activated MG-CM (1381.2 \pm 82.7 $\mathrm{pg} / \mathrm{ml}$ ). In contrast, TGF- $\beta 1$ levels were not significantly different in resting $(196.5 \pm 42.3 \mathrm{pg} / \mathrm{ml})$ or activated 


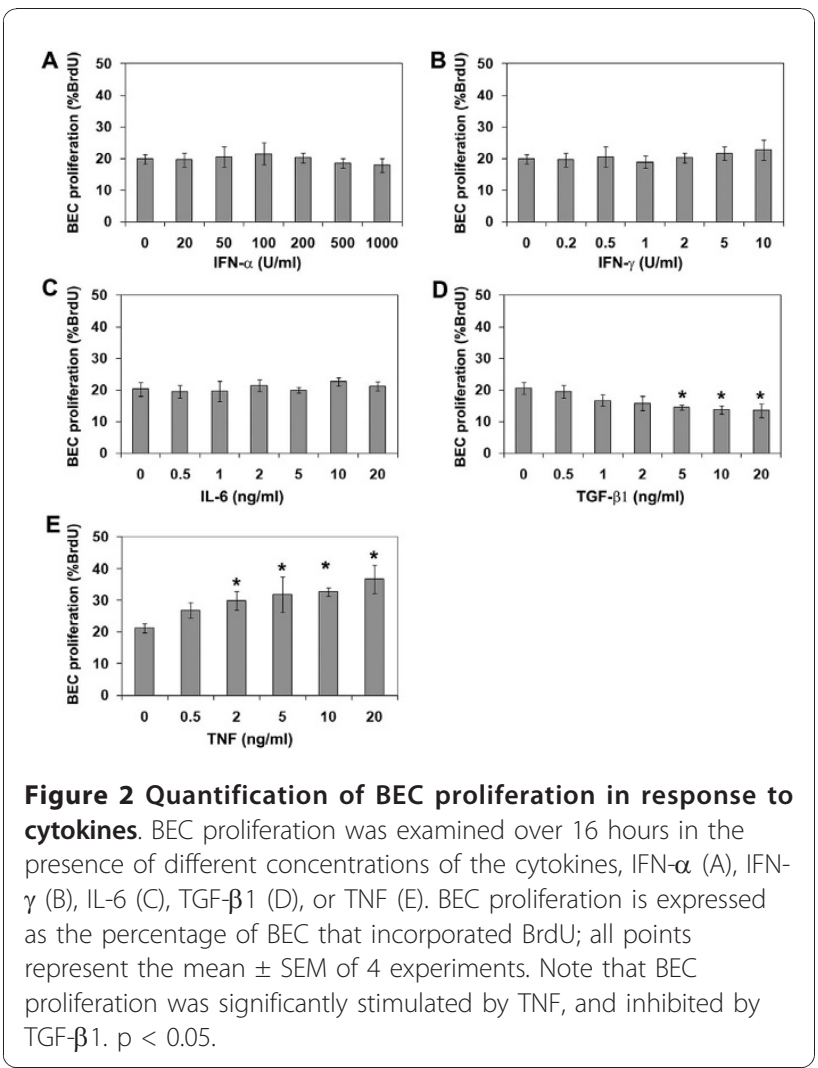

MG-CM (177.6 $\pm 43.4 \mathrm{pg} / \mathrm{ml})$ (Figure 3B). A-CM contained no TNF, either before or after activation (Figure $3 \mathrm{~A})$. A-CM did contain TGF- $\beta 1$, though this expression was not regulated by LPS treatment, and was at lower levels than MG-CM $(39.2 \pm 23.6 \mathrm{pg} / \mathrm{ml}$ and $75 \pm 20.5$ $\mathrm{pg} / \mathrm{ml}$ in resting and activated A-CM, respectively). Thus, microglial activation switches the TNF/TGF- $\beta 1$ balance heavily in favor of TNF.

\section{Microglial supernatants regulate BEC proliferation via TNF and TGF- $\beta 1$}

To address whether the influence of MG-CM on BEC proliferation is mediated by TNF or TGF- $\beta 1$, we examined the influence of resting or activated MG-CM on $\mathrm{BEC}$ proliferation in the presence of function-blocking antibodies directed against TNF or TGF- $\beta 1$. As shown in Figure 4A, compared to control conditions $(20.9 \pm$ $1.6 \%$ ), resting MG-CM (Con IgG) significantly inhibited BEC proliferation $(7.2 \pm 2.0 \%, \mathrm{p}<0.005)$. This effect was significantly released by the anti-TGF- $\beta 1$ antibody $(12.5 \pm 1.0 \%, \mathrm{p}<0.01)$. In contrast, compared to control conditions (19.7 $\pm 1.4 \%)$, activated MG-CM (Con IgG) significantly increased BEC proliferation $(29.2 \pm 1.7 \%$, p $<0.01$; Figure 4B), and this effect was significantly inhibited by the anti-TNF blocking antibody $(18.9 \pm 1.7 \%, \mathrm{p}<$ 0.01 ). This data strongly suggests that TGF- $\beta 1$ is in part responsible for the negative influence of resting MG-

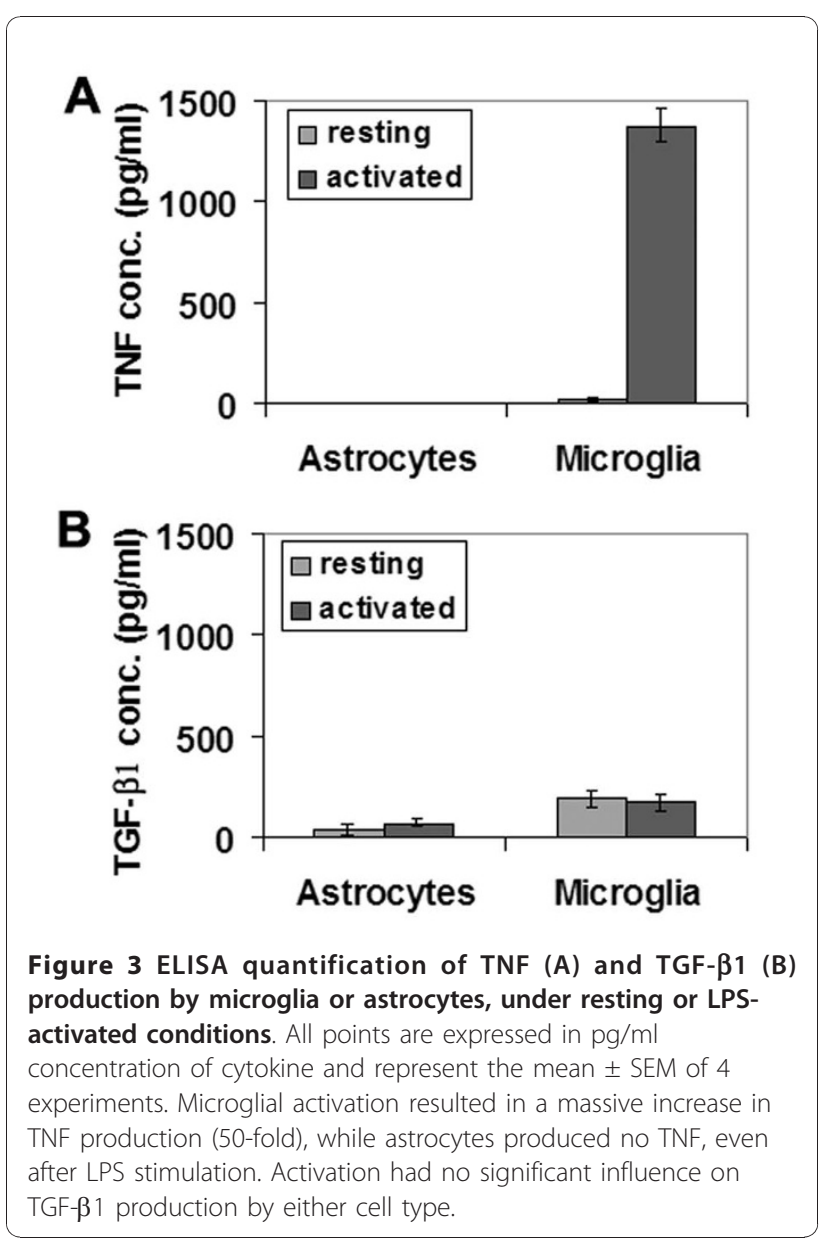

$\mathrm{CM}$ on BEC proliferation, and conversely, implicates TNF as a major factor responsible for the positive effect of activated MG-CM on BEC proliferation.

\section{Discussion}

Cerebral angiogenesis occurs in the adult CNS in a number of conditions, including cerebral ischemia [2], neoplasia [3], and the neuroinflammatory conditions multiple sclerosis [5], and Alzheimer's disease [4]. In these conditions, angiogenesis is often associated with microglial accumulation and activation $[17,18]$, raising the possibility that activated microglia may promote angiogenic events. In the current study, we directly examined this question in vitro, by exposing BEC to microglia-conditioned media. This revealed that microglia regulate $\mathrm{BEC}$ proliferation in a biphasic manner. Soluble factors from resting microglia inhibit, while those from activated microglia promote BEC proliferation, and these effects are largely attributable to the microglial cytokines TGF- $\beta 1$ and TNF, respectively. This data suggests that in vivo, microglial activation state might be an important determinant of the earliest stage of cerebral angiogenesis, namely endothelial cell 


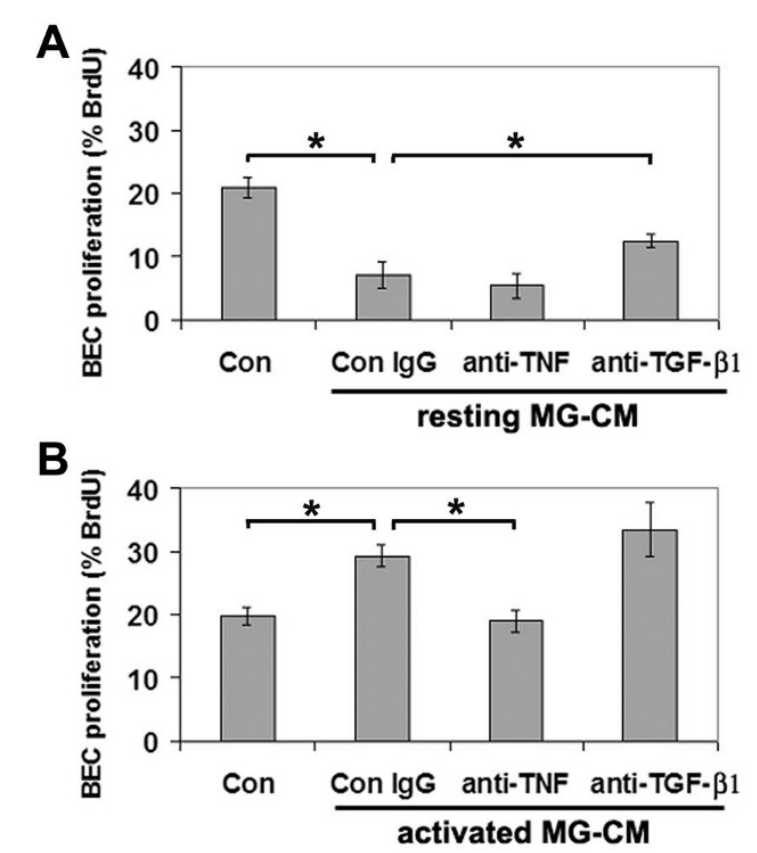

Figure 4 Function-blocking experiments to examine the role of TNF and TGF- $\beta 1$ in mediating the effects of MG-CM. BEC proliferation is expressed as the percentage of BEC that incorporated BrdU; all points represent the mean \pm SEM of 4 experiments. Note that the inhibitory influence of resting MG-CM was partially relieved by TGF- $\beta 1$ antibodies (A) and conversely, the mitogenic influence of activated MG-CM was abrogated by anti-TNF antibodies (B). $p<0.05$.

proliferation. This model predicts that in the normal CNS, tonic levels of TGF- $\beta 1$ inhibit BEC proliferation, but that during cerebral ischemia or other neuroinflammatory processes, activated microglia ramp up TNF production, which promotes BEC proliferation.

\section{Microglial activation and angiogenesis}

Microglia, as the primary immune effector cells in the CNS, play important roles in the surveillance and response to pathological insults. As the gatekeeper of the $\mathrm{BBB}$, microglia are well positioned to mount a rapid aggressive response to noxious stimuli that enter the CNS. Under normal conditions, microglia occupy a resting "on surveillance" phenotype, but after stimulation, switch to an activated highly migratory, mitogenic phenotype, with upregulated production of inflammatory cytokines such as TNF and IFN- $\gamma$ [21,24]. Within days of an ischemic insult, angiogenic remodeling can be observed at the ischemic penumbra $[15,16]$, and interestingly, angiogenic vessels are often surrounded by inflammatory microglia and macrophages $[17,18]$, suggesting that activated microglia and/or macrophages may be instrumental in promoting the angiogenic response to cerebral ischemia. While this idea has not yet been directly tested in the ischemic CNS, traumatic CNS injury leads to activation of microglia and macrophages, and drugs that block activation and proliferation of these cells, also inhibit neovascularization [25]. In addition, studies from outside the CNS support the concept that activated cells of the macrophage lineage directly promote angiogenic events. In tumor models, depletion of monocytes, the blood precursors of tissue macrophages, leads to marked reduction in tumor-associated angiogenesis [26], and conversely, addition of tissue macrophages strongly promotes neovascularization in corneal and rabbit ear chamber models $[27,28]$. Consistent with this, and in agreement with our own finding, conditioned media taken from activated macrophages directly promotes endothelial cell proliferation in vitro [29].

The influence of TNF and TGF- $\beta 1$ on angiogenic events Our studies suggest that the positive and negative influences of microglia on BEC proliferation is mediated, at least in part, by the antagonistic cytokines TNF and TGF- $\beta 1$, respectively. The influence of these cytokines on angiogenic events is still a matter of debate, with different studies demonstrating either pro- or anti-angiogenic effects, depending on the source of endothelial cells and the concentration of cytokine employed. TNF has been shown to both promote [30-32] and inhibit [33] angiogenic events, with one report demonstrating a negative effect of TNF on endothelial cell proliferation in vitro, but a stimulation of neovascularization in vivo [34], while another showed both positive and negative effects on endothelial cell proliferation, depending on the cellular source and cytokine combinations [35]. Similar apparently conflicting data have also been described for TGF- $\beta 1[7,36]$. In an attempt to reconcile these data, it has been suggested that the effects of these factors may have biphasic effects on angiogenesis, depending on cytokine concentration [36]. To directly investigate this possibility, we examined BEC proliferation across a wide range of cytokine concentrations, but in each case, this demonstrated a clear dose-response effect in one direction only, namely TNF promoting and TGF- $\beta 1$ inhibiting BEC proliferation. Significantly, recent data has shown that the biphasic effect of TNF on endothelial cells can be explained by antagonistic functions of the TNF receptors TNFR1 and TNFR2, with TNFR2 stimulating endothelial cell survival, migration, and angiogenesis, while TNFR1 inhibits these functions $[37,38]$. In the current study, close examination of the TGF- $\beta 1$ concentrations that mediated an inhibitory effect on BEC proliferation revealed an apparent difference in the potency of the endogenous form (present in resting MG-CM; $0.2 \mathrm{ng} / \mathrm{ml}$ ) when compared with the pure recombinant form $(5 \mathrm{ng} / \mathrm{ml})$. Two reasons may 
explain this discrepancy. First, while the effect of recombinant TGF- $\beta 1$ did not reach statistical significance until a concentration of $5 \mathrm{ng} / \mathrm{ml}$, it did have an inhibitory trend at lower concentrations $(0.5-1 \mathrm{ng} / \mathrm{ml})$. Second and perhaps more important, in this study we used the human recombinant form of TGF- $\beta 1$, and it is entirely plausible that the biological activity of this form on mouse BEC may not be as high as the endogenous murine form.

In summary, our data provides evidence that microglia, the principal immune effector cells in the CNS, can regulate $\mathrm{BEC}$ proliferation in a biphasic manner by altering the balance of TNF and TGF- $\beta 1$. As BEC proliferation is an early stage of the angiogenic process, and new vessel formation leads to increased cerebral blood flow [39] and clinical outcome [40,41], our findings suggest that a controlled level of microglial activation and TNF release might prove beneficial in the treatment of stroke patients by promoting BEC proliferation and subsequent neovascularization. In light of the recent finding that microglia protect neurons from ischemia via a TNF-mediated mechanism [42], this approach has the potential to stimulate a positive outcome via two separate mechanisms.

\section{Conclusions}

Our data demonstrate that microglia regulate BEC proliferation in a biphasic manner; microglia conditioned medium (MG-CM) from resting microglia inhibit, while that from activated microglia promote BEC proliferation. BEC proliferation was also inhibited by TGF- $\beta 1$, but promoted by TNF. ELISA showed that TNF and TGF$\beta 1$ are both present in MG-CM, and that while TGF- $\beta 1$ dominated in resting MG-CM, TNF levels were massively increased in activated MG-CM, shifting the balance in favor of TNF. Antibody-blocking studies revealed that the influence of MG-CM to inhibit or promote BEC proliferation was largely attributable to the cytokines TGF- $\beta 1$ and TNF, respectively. Taken together, this data suggests that microglial activation state might be an important determinant of BEC proliferation, an early event in cerebral angiogenesis.

\section{Acknowledgements}

This work was supported in part by a Harry Weaver Neuroscience Scholar Award (JF 2125A1/1) from the National Multiple Sclerosis Society (RM), and by NIH grant RO1 NS060770. This is manuscript number 20532 from The Scripps Research Institute.

\section{Authors' contributions}

JW prepared the cell cultures, carried out the biochemical analysis and contributed to drafting the manuscript. LL participated in the design of the study and also assisted in manuscript preparation. RM conceived of the study, performed the proliferation studies, and helped to draft the manuscript. All authors read and approved the final manuscript.

\section{Competing interests}

The authors declare that they have no competing interests.

Received: 5 October 2010 Accepted: 6 December 2010

Published: 6 December 2010

\section{References}

1. Marin-Padilla M: Early vascularization of the embryonic cerebral cortex: Golgi and electron microscopic studies. J Comp Neurol 1985, 241:237-249.

2. Hayashi T, Noshita N, Sugawara T, Chan PH: Temporal profile of angiogenesis and expression of related genes in the brain after ischemia. J Cereb Blood Flow Metab 2003, 23:166-180.

3. Plate KH, Risau W: Angiogenesis in malignant gliomas. Glia 1995, 15:339-347.

4. Desai BS, Schneider JA, Li JL, Carvey PM, Hendey B: Evidence of angiogenic vessels in Alzheimer's disease. J Neural Transm 2009, 116:587-597.

5. Holley JE, Newcombe J, Whatmore JL, Gutowski NJ: Increased blood vessel density and endothelial cell proliferation in multiple sclerosis cerebral white matter. Neuosci Lett 2010, 470:65-70.

6. Millauer B, Wizigmann-Voos S, Schnurch $H_{1}$ Martinez R, Moller NP, Risau W, Ulrich A: High affinity VEGF binding and developmental expression suggest Flk-1 as a major regulator of vasculogenesis and angiogenesis. Cell 1993, 72:835-846.

7. Roberts AB, Sporn MB, Assoian RK, Smith JM, Roche NS, Wakefield U, Heine I, Liotta A, Falanga J, Kehrl JH, Fauci AS: Transforming growth factor type $b$ : rapid induction of fibrosis and angiogenesis in vivo and stimulation of collagen formation in vitro. Proc Natl Acad Sci 1986, 83:4167-4171

8. Stromblad S, Cheresh DA: Integrins, angiogenesis and vascular cell survival. Chem Biol 1996, 3:881-885.

9. Kuo N-T, Benhayon D, Przybylski RJ, Martin RJ, LaManna JC: Prolonged hypoxia increases vascular endothelial growth factor mRNA and protein in adult mouse brain. J Appl Physiol 1999, 86:260-264.

10. Pichiule $P$, LaManna JC: Angiopoietin-2 and rat brain capillary remodeling during adaptation and de-adaptation to prolonged mild hypoxia. J Appl Physiol 2002, 93:1131-1139.

11. Astrof $S$, Hynes RO: Fibronectins in vascular development. Angiogenesis 2009, 12:165-175.

12. Milner R, Hung S, Erokwu B, Dore-Duffy P, LaManna JC, del Zoppo GJ: Increased expression of fibronectin and the a5 $\beta 1$ integrin in angiogenic cerebral blood vessels of mice subject to hypobaric hypoxia. Mol Cell Neurosci 2008, 38:43-52.

13. Milner R, Campbell IL: Developmental regulation of $\beta 1$ integrins during angiogenesis in the central nervous system. Mol Cell Neurosci 2002, 20:616-626.

14. del Zoppo GJ, Milner R: Integrin-matrix interactions in the cerebral microvasculature. Arterioscler Thromb Vasc Biol 2006, 26:1966-1975.

15. Chen $\mathrm{HH}$, Chien $\mathrm{CH}$, Liu HM: Correlation between angiogenesis and basic fibroblast growth factor expression in experimental brain infarct. Stroke 1994, 25:1651-1657.

16. Wei L, Erinjeri JP, Rovainen CM, Woolsey TA: Collateral growth and angiogenesis around cortical stroke. Stroke 2001, 32:2179-2184.

17. Jander S, Schroeter M, D'Urso D, Gillen C, Witte OW, Stoll G: Focal ischaemia of the rat brain elicits an unusual inflammatory response: early appearance of CD8+ macrophages/microglia. Eur J Neurosci 1998, 10:680-688.

18. Manoonkitiwongsa PS, Jackson-Friedman C, McMillan PJ, Schultz RL, Lyden PD: Angiogenesis after stroke is correlated with increased numbers of macrophages: The clean-up hypothesis. J Cereb Blood Flow Metab 2001, 21:1223-1231.

19. Milner R, Hung S, Wang X, Berg G, Spatz M, del Zoppo G: Responses of endothelial cell and astrocyte matrix-integrin receptors to ischemia mimic those observed in the neurovascular unit. Stroke 2008, 39:191-197.

20. Crocker SJ, Frausto RF, Whitton JL, Milner R: A novel method to establish microglia-free astrocyte cultures: comparison of matrix metalloproteinase expression profiles in pure cultures of astrocytes and microglia. Glia 2008, 56:1187-1198.

21. Hanisch UK, Kettenmann H: Microglia: active sensor and versatile effector cells in the normal and pathologic brain. Nat Neurosci 2007, 10:1387-1394 
22. Gregersen R, Lambertsen K, Finsen B: Microglia and macrophages are the major source of tumor necrosis factor in permanent middle cerebral artery occlusion in mice. J Cereb Blood Flow Metab 2000, 20:53-65.

23. Lehrman E, Kiefer R, Christensen T, Toyka KV, Zimmer J, Diemer NH, Hartung H-P, Finsen B: Microglia and macrophages are major sources of locally produced transforming growth factor-beta 1 after transient middle cerebral artery occlusion in rats. Glia 1998, 24:437-448.

24. Carson MJ: Microglia as liasons between the immune and central nervous systems: functional implications for multiple sclerosis. Glia 2002, 40:218-231.

25. Giulian D, Chen J, Ingeman JE, George JK, Noponen M: The role of mononuclear phagocytes in wound healing after traumatic injury to adult mammalian brain. J Neurosci 1989, 9:4416-4429.

26. Evans R: Effect of X-irradiation on host-cell infiltration and growth of a murine fibrosarcoma. Br J Cancer 1977, 35:557-566.

27. Hunt TK, Knighton DR, Thakral KK, Goodson WHr, Andrews WS: Studies on inflammation and wound healing: angiogenesis and collagen synthesis stimulated in vivo by resident and activated wound macrophages. Surgery 1984, 96:48-54.

28. Thakral KK, Goodson WHr, Hunt TK: Stimulation of wound blood vessel growth by wound macrophages. J Surg Res 1979, 26:430-436.

29. Polverini PJ, Cotran PS, Gimbrone MAJ, Unanue ER: Activated macrophages induce vascular proliferation. Nature 1977, 269:804-806.

30. Baluk P, Yao LC, Feng J, Romano T, Jung SS, Schreiter JL, Yan L, Shealy DJ, McDonald DM: TNF-alpha drives remodeling of blood vessels and lymphatics in sustained airway inflammation in mice. J Clin Invest 2009, 119:2954-2964.

31. Leibovich SJ, Polverini PJ, Shepard HM, Wiseman DM, Shively V, Nuseir N: Macrophage-induced angiogenesis is mediated by tumour necrosis factor -a. Nature 1987, 329:630-632.

32. Sainson RC, Johnston DA, Chu HC, Holderfield MT, Nakatsu MN, Crampton SP, Davis J, Conn E, Hughes CC: TNF primes endothelial cells for angiogenic sprouting by inducing a tip cell phenotype. Blood 2008, 111:4997-5007.

33. Schweigerer L, Malerstein B, Gospodarowicz D: Tumor necrosis factor inhibits the proliferation of cultured capillary endothelial cells. Biochem Biophys Res Commun 1987, 143:997-1004.

34. Fràter-Schröder M, Risau W, Hallmann R, Gautschi P, Böhlen P: Tumor necrosis factor type alpha, a potent inhibitor of endothelial cell growth in vitro, is angiogenic in vivo. Proc Natl Acad Sci 1987, 84:5277-5281.

35. Gerol M, Curry L, McCarroll L, Doctrow S, RayChaudhury A: Growth regulation of cultured endothelial cells by inflammatory cytokines: mitogenic, anti-proliferative and cytotoxic effects. Comp Biochem Physiol C Pharmacol Toxicol Endocrinol 1998, 120:397-404.

36. Pepper MS, Vassalli JD, Orci L, Montesano R: Biphasic effect of transforming growth factor beta 1 on in vitro angiogenesis. Exp Cell Res 1993, 204:356-363

37. Luo D, Luo Y, He Y, Zhang H, Zhang R, Li X, Dobrucki WL, Sinusas AJ, Sessa WC, Min W: Differential functions of tumor necrosis factor receptor 1 and 2 signaling in ischemia-mediated arteriogenesis and angiogenesis. Am J Pathol 2006, 169:1886-1898.

38. Goukassian DA, Qin G, Dolan C, Murayama T, Silver M, Curry C, Ealton E, Luedermann C, Ma H, Asahara T, et al: Tumor necrosis factor-alpha receptor p75 is required in ischemia-induced neovascularization. Circulation 2007, 115:752-762.

39. Chen Y, Xu B, Arderiu G, Hashimoto T, Young WL, Boudreau NJ, Yang GY: Retroviral delivery of homeobox D3 gene induces cerebral angiogenesis in mice. J Cereb Blood Flow Metab 2004, 24:1280-1287.

40. Krupinski J, Kaluza J, Kumar P, Kumar S, Wang JM: Role of angiogenesis in patients with cerebral ischemic stroke. Stroke 1994, 25:1794-1798.

41. Weiller C, Ramsay SC, Wise RJ, Friston KJ, Frackowiak RS: Individual patterns of functional reorganization in the human cerebral cortex after capsular infarction. Ann Neurol 1993, 33:181-189.

42. Lambertsen KL, Clausen BH, Babcock AA, Gregersen R, Fenger C, Nielsen HH, Haugaard LS, Wirenfeldt M, Nielsen M, Dagnaes-Hansen F, et al: Microglia protect neurons against ischemia by synthesis of tumor necrosis factor. J Neurosci 2009, 29:1319-1330.

doi:10.1186/1742-2094-7-89

Cite this article as: Welser et al: Microglial activation state exerts a biphasic influence on brain endothelial cell proliferation by regulating the balance of TNF and TGF- $\beta 1$. Journal of Neuroinflammation 2010 7:89.

\section{Submit your next manuscript to BioMed Central and take full advantage of:}

- Convenient online submission

- Thorough peer review

- No space constraints or color figure charges

- Immediate publication on acceptance

- Inclusion in PubMed, CAS, Scopus and Google Scholar

- Research which is freely available for redistribution

Submit your manuscript at www.biomedcentral.com/submit 